\title{
Assessment of Arsenic poisoning among printing textile workers in Baghdad.
}

\author{
Ali A. Ali sahib* DCM, FICMS
}

$\underline{\text { Abstract }}$

Background: Workers of textile industry are mainly exposed to a variety of toxic dyes, bleaching agents, salts, acids, alkalis and heavy metals like arsenic through evaporation and inhale by workers or direct skin contact during the textile mordant process and possibly health effect through the printing process

Objectives : to assess the health effects of mild to moderate long term exposure to Arsenic trioxide on textile printing workers and to evaluate and compare the clinical utility of blood and urine arsenic for

J Fac Med Baghdad 2017; Vol.59, No .3 Received Aug. 2017 Accepted Oct. 2017 predicting arsenic poisoning.

Methods: In this historic cohort study, measurement of serum and urine levels of arsenic of 65exposed workers and 63non exposed workers was carried out during march 2014 through march 2015 All of the studies cases were worked in a cotton textile factories and considered as target population for detection of any possible industrial chronic arsenic exposure associated sign and symptoms. The non-exposed workers were randomly selected from office personnel of the same factories. Clinical examination, signs and symptoms and a questionnaire method used for analysis in both groups.

Results: both groups have a similar age structure. Statistical difference was present between the serum arsenic and arsenic in urine mean values for both the exposed and non-exposed groups. The prevalence ratio for the exposure was higher than one for arsenic in urine. The best cut-off values of arsenic in urine to diagnosis arsenic poisoning based on Receiver operating characteristic curve analysis( ROC) was $>90 \mu \mathrm{g} / \mathrm{L}$ and the areas under the curve equal to 0.98 was determined for the prediction early chronic arsenic poisoning.

Conclusion: measurement of arsenic in urine in early stage was useful to detect mild to moderate health effects based on Receiver operating characteristic curve analysis (ROC) among textile printing workers exposed to arsenic.

Keywords: arsenic, textile printing workers, flameless chromatography, ROC curve.

\section{Introduction:}

Arsenic, element 33, has a long and nefarious history; its name has become synonymous with poison. In the 15 th and 16 th centuries, the Italian family of Borgias used arsenic as their favorite poison for political assassinations. Some even have suggested that Napoleon was poisoned by arsenictainted wine served to him while in exile(1). According to the American Association of Poison Control Centers' (AAPCC) National Poisoning Data System (NPDS), 3 patients suffered major effects and 1 died from exposure to non pesticide arsenic exposure in 2015(2). On the other hand thousands and thousands of people are suffering from the toxic effects of arsenicals in many countries all over the world due to industrial effluent (3). Arsenic, being a normal component of human body is transported by the blood to different organs in the body (4). However the textile industry is one such source that grew out of the industrial revolution in the 18th century as mass production of clothing became a mainstream industry(5). Workers of textile industry are mainly exposed to a variety of toxic dyes, bleaching agents, salts, acids, alkalis and heavy metals like arsenic and possibly health effect such as

*Dept. of family \& Community Medicine/ College of Medicine/University of Al-Nahrain

E-mail: alisahb557@gmail.com dyes, organic solvents and fixatives throughout the printing process $(6)$.

Arsenic trioxide (As2O3), or white arsenic, is useful in the purification of synthesis gas and as a primary material for all arsenic compounds. It is also a preservative for hides and wood, a textile mordant, a reagent in mineral flotation, and a decolorizing and refining agent in glass manufacture(7).

Arsenic is evaporate and inhale by workers during the textile mordant process(8). In direct contact it is an irritant to the skin and may cause eczematous dermatitis and arsenical keratosis usually on the palms and soles on contact(9). . Chronic toxic effects include megaloblastic bone marrow suppression and liver enlargement but may also affect higher nervous functions like cognition and personality changes $(10,11)$.

The textile printing industry in Iraq employs a large number of workers that may possibly be exposed to toxic compounds. Regarding the increase in the number of such workers in our country and no study conducted about the problem, I design this study..

\section{Subjects, Materials and Methods}

A historic cohort study based on knowledge of duration of exposure or work was conducted among convenient sample in a textile printing workers at cotton textile plant in Baghdad (the largest textile 
factory in capital Baghdad, Iraq).and the laboratory investigations were done in National Center of Occupational Health and Safety(the specialized center for occupational health and safety NOHS')Baghdad, that lasted 1year (march 2014-march2015) The NOHS is a referral center for patients from greater Baghdad area. The objective of this center is to closely monitor workers and workplaces to ensure healthy and safety environment of workplaces and early detection of any abnormal health and safety conditions at workplaces.

Exclusion criteria included duration of employment less than one year, smoking, drinking ground water , workers must not have consumed seafood for at least 3 days prior to urine collection; laboratory must "speciate" the arsenic into organic and inorganic moieties, because the inorganic form is responsible for symptoms and signs of arsenic toxicity $(12,13)$, workers exposed to arsenic rather than textile industry .The study consist of 125 workers recruited in the textile plant fulfilled the inclusion criteria( 65 exposed workers were compared to 63 control workers who already work in the plant as overseers .

The data collection: After explaining the objectives of the study to the workers and taking their verbal consent, the data were collected from the workers by using specially construct questionnaire.

Demographic data gather in the questionnaire include age, sex, tobacco smoking, past medical history, work history including any changes of the job and second job and review all available clinical records.

A thorough clinical examination, signs and symptoms, with special attention to the signs that may be related or associated with arsenic exposure such as anemia, Hyper pigmentation, Polyneuritis and motor paralysis, esophagitis, Enlarged and tender liver , Rhino-pharyngo-laryngitis was performed by consultant in occupational and environmental medicine. Whole blood samples were thaw from the workers through a venipuncture using $5 \mathrm{ml}$ of the blood and dilute with $1 \% \mathrm{HNO} 3+$ $1 \%$ Methanol $+0.2 \%$ Triton $\mathrm{X}-100+0.5 \% \mathrm{NH} 4 \mathrm{OH}$. Samples are then centrifuge for 10 minutes at 3500 rpm for the determination of arsenic concentration in blood and total arsenic measurement in human urine will measure by the Flameless atomic absorption and laboratory tests include a hemoglobin level .By WHO criteria ,anemia is defined as a hemoglobin concentration lower than $13 \mathrm{~g} / \mathrm{dl}$ in men(14). Normal Human Levels Levels of arsenic in unexposed individuals: $<1 \mu \mathrm{g} / \mathrm{L}$ in blood $100 \mu \mathrm{g} / \mathrm{L}$ in urine (15) all these biochemical investigations were performed in the laboratories of National Center of Occupational Health and Safety in Baghdad.

Data were entered and analyzed by MINI TAB soft ware version 13 . Statistical analysis was done by using: Descriptive statistic: tables (frequency and percentage) Inferential statistic: t-test was used to test the statistical differences between group means. The receiver operating characteristics curve was done by using SPSS software version 16. ROC analysis is related in a direct and natural way to cost/benefit analysis of diagnostic decision making .ROC analysis provides tools to select possibly optimal models and to discard suboptimal ones independently from (and prior to specifying ) the cost context or the class distribution and therefore has been used in medicine therefore the receiver operating characteristic (ROC) curve is the plot that displays the full picture of trade-off between the sensitivity of test measurement of arsenic in urine $\mathrm{m}$ (true positive rate) and (1- specificity), of test measurement of arsenic in urine, (false positive rate) across a series of cut-off points(15). Area under the ROC curve is considered as an effective measure of inherent validity of a diagnostic test and total area under ROC curve is a single index for measuring the performance a test so the larger the area under curve( AUC), the better is overall performance of the medical test to correctly identify diseased and non-diseased subjects(16). All comparisons were accepted as significant when $\mathrm{P}$ - value equal or less than 0.05 .

\section{Results:}

Sixty five workers occupationally exposed to arsenic were studied and compared with 63 non-exposed workers. Both groups have a similar age structure (table 1) with mean of $37.2 \pm 7.90$ years for the exposed and a mean of $35.92 \pm 9.25$ years for the non-exposed workers. No statistical difference could be detected between the two mean age $(p>0.05)$. The majority $32(49.43 \%)$ of the exposed workers and 29 $(45.31 \%)$ of the non exposed workers fall in the age group 30-39 years. All workers (exposed and unexposed were males), and all of them were Iraqis .The mean duration of employment for the exposed workers was $6.22 \pm 4.21$ years, $29(45.31 \%$ ) have a duration of employment 1-5 years and quite a large number $21(32.30 \%)$ have a duration of employment 6- 10 years (table 2). Table 3 shows positive clinical findings relevant to the arsenic exposure in exposed and non-exposed textile printing workers . Arsenical keratosis was detected in $7.69 \%$ of the exposed and in $3.17 \%$ of the non exposed workers .Exposure to arsenic carries more than twice the risk for developing keratosis (prevalence ratio $=2.38$, $95 \% \mathrm{CI}=0.48-11.8$ ). Eczematous dermatitis was found in $3.07 \%$ of the exposed while none of the non exposed workers had such a finding. Hyper pigmentation was detected in $4.61 \%$ of the exposed and in $1.58 \%$ of the non-exposed which carries a prevalence ratio of 2.86 and a 95\% CI of 0.31 26.58. Table 4 shows a past medical history and symptoms relevant to arsenic exposure among studied sample. Anemia was detected in $26.15 \%$ of the exposed and in $7.93 \%$ of the non exposed workers .Exposure to arsenic carries approximately twice the risk for developing anemia $(\mathrm{PR}=1.80$, $95 \% \mathrm{CI}=0.87-3.74)$. polyneuritis was found in $3.07 \%$ of the exposed while one of the non exposed workers had such a finding which carries a prevalence ratio of 1.91 and a $95 \%$ CI of 0.18 20.49. Hyper pigmentation was detected in $21.53 \%$ of the exposed and in $3.17 \%$ of the non-exposed 
which carries a prevalence ratio of 1.53 and a $95 \%$ CI of 0.53- 4.44.. Rhino-pharyngo-laryngitis was found in 4.61 of the exposed while and in $3.17 \%$ of the non exposed which carries a prevalence ratio of 1.43 and a $95 \%$ CI of 0.25- 8.38. Table (5) shows urine and serum arsenic level in exposed and non exposed textile printing workers. There was statistically significant difference between urine arsenic mean values for both the exposed and nonexposed groups $(p<0.05)$. The best cut-off values of arsenic in urine to detect early chronic arsenic poisoning based on ROC curve analysis was $>90$ $\mu \mathrm{g} / \mathrm{L}$ and the areas under the curve equal to 0.98 . The sensitivities and false-positive rates according to receiver operating characteristic curve were as Following:
Sensitivity $=98 \%$, Specificity $=100 \%$, Positive predictive value $=100 \%$ Negative predictive value $=98 \%$ as shown in table (6).

Table (1) age distribution of exposed and non exposed workers to arsenic.

\begin{tabular}{|c|c|c|c|c|}
\hline $\begin{array}{l}\text { Age } \\
\text { group } \\
\text { (years) } \\
\end{array}$ & $\begin{array}{l}\text { Number of } \\
\text { exposed } \\
\text { workers }=65\end{array}$ & $\begin{array}{l}\text { Number of } \\
\text { unexposed } \\
\text { workers }=63\end{array}$ & total & p-value \\
\hline $20-29$ & 12 & 13 & 25 & \multirow{5}{*}{$\begin{array}{l}\text { D.f=3 } \\
\chi 2=1.028 \\
P=>0.05\end{array}$} \\
\hline $30-39$ & 32 & 29 & 61 & \\
\hline $40-49$ & 13 & 16 & 29 & \\
\hline $50-59$ & 8 & 5 & 13 & \\
\hline Total & 65 & 63 & 126 & \\
\hline
\end{tabular}

Table (2) duration of employment for workers exposed to arsenic.

\begin{tabular}{ccc}
\hline $\begin{array}{c}\text { Duration of employment } \\
\text { (year) }\end{array}$ & $\begin{array}{c}\text { Number } \\
\text { of } \\
\text { workers }\end{array}$ & $\begin{array}{c}\text { Percent of } \\
\text { total(n=65) }\end{array}$ \\
\hline$\leq 1$ & 4 & 6.25 \\
\hline $1-5$ & 29 & 45.31 \\
\hline $6-10$ & 23 & 35.94 \\
\hline$\geq 10$ & 9 & 12.50 \\
\hline total & 65 & $100 \%$ \\
\hline
\end{tabular}

Table (3)clinical findings relevant to skin disease in arsenic exposed and non-exposed workers.

\begin{tabular}{|c|c|c|c|c|c|c|}
\hline Clinical findings & $\begin{array}{l}\text { Number of } \\
\text { exposed } \\
\text { workers }(65)\end{array}$ & Percentage & $\begin{array}{l}\text { Number of non- } \\
\text { exposed } \\
\text { workers }(63)\end{array}$ & Percentage & PR & $95 \% \mathrm{CI}$ for $\mathrm{PR}$ \\
\hline arsenical keratosis & 5 & 7.69 & 2 & 3.17 & 2.38 & $0.84-11.83$ \\
\hline eczematous dermatitis & 2 & 3.07 & 0 & 0 & $\begin{array}{ll}---- \\
--1\end{array}$ & ------ \\
\hline hyperpigmentation & 3 & 4.61 & 1 & 1.58 & 2.86 & $0.31-26.58$ \\
\hline
\end{tabular}

Table (4) past medical history and symptoms relevant to arsenic exposure among

\begin{tabular}{lllllll}
\hline $\begin{array}{l}\text { Medical history } \\
\text { and symptoms }\end{array}$ & $\begin{array}{l}\text { Number of } \\
\text { exposed } \\
\text { workers } \\
(\mathrm{N}=65)\end{array}$ & percentage & $\begin{array}{l}\text { Number of non } \\
\text { exposed workers } \\
(\mathrm{N}=63)\end{array}$ & percentage & PR & 95\%CI for prevalence ratio \\
\hline polyneuritis & 2 & 3.07 & 1 & 1.5 & 1.90 & $0.18-20.49$ \\
\hline anemia & 17 & 26.15 & 5 & 3.17 & 1.80 & $0.87-3.74$ \\
\hline $\begin{array}{l}\text { hyper } \\
\text { pigmentation }\end{array}$ & 14 & 21.53 & 2 & 1.53 & 1.43 & $0.53-4.44$ \\
\hline $\begin{array}{l}\text { Rhino-pharyngo- } \\
\text { laryngitis }\end{array}$ & 3 & 4.61 & 1 & $0.25-8.33$ \\
\hline
\end{tabular}

Table(5) urine and serum arsenic level in exposed and non exposed textile printing workers.

\begin{tabular}{lllll}
\hline Laboratory test & $\begin{array}{l}\text { mean } \pm \text { sd of } \\
\text { Exposed } \\
\mathrm{n}=(65)\end{array}$ & $\begin{array}{l}\text { mean } \pm \text { sd of Non }- \\
\text { exposed } \\
\mathrm{N}=63\end{array}$ & t-test & p-value \\
\hline serum arsenic level & $39 \pm 11.5$ & $10 \pm 13.22$ & -0.47 & $\mathrm{P}>0.05$ \\
\hline Urine arsenic level & $120 \pm 17.33$ & $40 \pm 15.31$ & 2.54 & $\mathrm{P}<0.05$ \\
\hline
\end{tabular}

Table (6): Showed The best cut-off values of arsenic in urine based on ROC curve analysis.

\begin{tabular}{lllll}
\hline $\begin{array}{l}\text { Cutoff } \\
\text { point }\end{array}$ & Control(63) & exposed (65) & $\begin{array}{l}\text { Area } \\
\text { under } \\
\text { curve }\end{array}$ & p-value \\
\hline$>90$ & 0 & 64 & 0.98 & $<0.001$ \\
\hline$\leq 90$ & 63 & 1 & & \\
\cline { 1 - 3 } Total & 63 & 65 & & \\
\hline
\end{tabular}

The best cut-off values of arsenic in urine to diagnosis mild and moderate chronic arsenic poisoning based on ROC curve analysis was $>90$ $\mu \mathrm{g} / \mathrm{L}$ and the areas under the curve equal to 0.98 .as shown in table (6).
The sensitivities and false-positive rates according to receiver operating characteristic curve were as following:

Sensitivity $=98 \%$, Specificity $=100 \%$, Positive predictive value $=100 \%$

Negative predictive value $=98 \%$

The sensitivities and false-positive rates by using receiver operating characteristic curve analysis(ROC) for the early detection of chronic arsenic poisoning by measurement of urine arsenic concentration was shown in Fig. 1. The areas under the curve equal to 0.98 was determined for the prediction of arsenic poisoning. 
ROC Curve

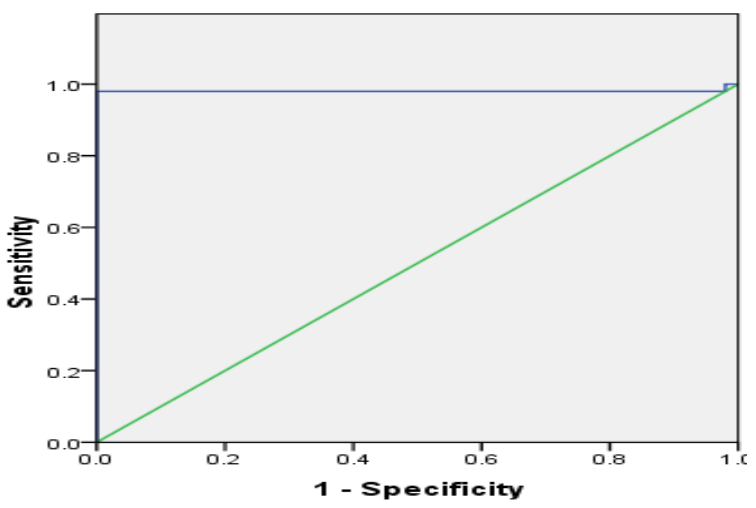

Figure(1): ROC curve analysis of data in textile printing workers exposed to arsenic

\section{Discussion:}

Unfortunately, little is known about occupational arsenic poisoning among printing textile workers in developed and developing societies because most studies related to the public health concern of chronic exposure to arsenic in drinking water. Therefore, the current study sought to contribute to a better understanding of occupational arsenic poisoning among textile printing workers in teaching. This study was evaluation the prevalence of abnormal arsenic level in urine and blood test among printing textile workers, the main illnesses of workers that associated with mild to moderate arsenic poisoning and evaluate and compare the clinical utility of blood and urine arsenic for predicting early arsenic poisoning. Such limitations with this study are that the number of workers included was relatively small, possible shift of workers from exposed to unexposed group and vice versa. Therefore larger prospective studies are needed to determine whether findings in this study are purely related to chronic exposure to arsenic as well as 24 urine collection of urine could be used as early clinical relevant predictor and little references available about occupational arsenic poisoning among printing textile worker .

Clinically symptoms associated with chronic exposure to arsenic were mainly that of skin changes including darkening or discoloration, redness, swelling, hyperkeratosis, whitish lines. Both sensory and motor nerve defects can develop. Additionally, liver and kidney function may be altered .Also associated with certain cancers (17) .In our study low values of skin changes may explained on the basis of low exposure levels, and that skin changes associated with long term exposure levels are sometimes accompanied by some neurologic manifestations(16) . Such neurologic manifestations were low rate in present study. Clinical features that could mainly be associated with chronic exposure to arsenic include liver disease, kidney disease, sensory and motors nerve ,anemia, upper respiratory tract and esophagitis (18) .The low rate of these clinical features in this study may also due to effect of transfer from one to another section in the studied factory because workers in the factory move around among different places at different intervals during the year depending on factory needs and priority ,hence they might be exposed to different(usually lower) concentration of arsenic than actually suggested by their working shift time. This study showed variation in measurement of arsenic in blood and 24hours collection of urine levels in exposed and none exposed workers this related to the fact that the blood concentrations of arsenic are elevated for a short time after exposure, after which arsenic rapidly disappears into tissues because if its affinity for tissue proteins. So measurement of urine arsenic is the preferred method of screening for arsenic exposure and blood is not a good specimen to screen for arsenic (19). In summary the results of present study indicate that although the laboratory results were all within low rate but arsenic poisoning among textile printing workers is still possible and should be given full attention in the medical surveillance of the workers and as differential validity between two groups (exposed and none exposed), using cutoff value of $90 \mu \mathrm{g} / \mathrm{ml}$, sensitivity was $98 \%$, specificity was $100 \%$, predictive value was $100 \%$. So measurement of arsenic in urine in early stage was useful detect mild to moderate chronic health effects among workers exposed to arsenic depending on cutoff value of $>90 \mu \mathrm{g} / \mathrm{L}$ which considered as a toxic level for arsenic poisoning depending on Receiver operating characteristic curve analysis ( ROC) of data .

\section{References:}

1-Gensheimer KF, Rea V, Mills DA, Montagna CP, Simone K. Arsenic poisoning caused by intentional contamination of coffee at a church gathering--an epidemiological approach to a forensic investigation. J Forensic Sci. 2010 Jul. 55(4):11169.

2-Mowry JB, Spyker DA, Brooks DE, Zimmerman A, Schauben JL. 2015 Annual Report of the American Association of Poison Control Centers' National Poison Data System (NPDS): 33rd Annual Report. Clin Toxicol (Phila). 2016 Dec. 54 (10):924-1109.

3-Mandal B.K. and Suzuki K.T., "Arsenic round the world: a review," Talanta, 2002, 58(1): 201-235.

4-Rasheed H., Slack R. and Kay P., "Human health risk assessment for arsenic: a critical review," Critical Reviews in Environmental Science and Technology, 2016.

5-Griffiths, Trevor; Hunt, Philip; O’Brien, Patrick. "Scottish, Irish, and imperial connections: Parliament, the three kingdoms, and the mechanization of cotton spinning in eighteenthcentury Britain," Economic History Review, Aug 2008, Vol. 61 Issue 3, pp 625-650

6-Albina, M.L., B. Montserral, J.S. Domenec and Jose L Domingo: Evaluation of the protective activity of defriprone, an aluminum chelator on aluminum induced developmental toxicity in mice. Teratology, 2000, 62, 86-92. 
7-U.S. Environmental Protection Agency/Office of Pesticide Program's Chemical Ingredients Database on Arsenic Trioxide (1327-53-3). Available at ( http://npirspublic.ceris.purdue.edu/ppis/), accessed may2017. Last update 17, may 2017. 8-ToxGuideTM for Arsenic. Available at https://www.atsdr.cdc.gov/toxguides/toxguide-2.pdf) , accessed may2017. Last update 17, may 2017. 10-Garcia-Vargas GG, Cebri in ME. Health effects of arsenic. In: Wang LW, ed. Toxicology of metals. Boca Raton: CRC Press; 1996: 423-438.

11-Cox TM, Jack N, Lofthouse S, et al. King George III and porphyria: an elemental hypothesis and investigation. Lancet. 2005;366:332 -335.

12-Rom, William N., Environmental and Occupational Medicine,4TH Edition, Lippincott Williams \& Wilkins ,2007,1007-1017.

13-Yoshimura Y, Endo Y, Shimoda Y, Yamanaka K, Endo G. Acute Arsine Poiosning Confirmed by Speciation Analysis of Arsenic Compounds in the Plasma and urine by HPLC-ICP-MS. J Occupational Health. Nov 2011. 53:45-49.

14- Blanc B, Finch CA, Hallberg L, et al. Nutritional anaemias. Report of a WHO Scientific Group. WHO Tech Rep Ser. 1968;405: 1-40.

15-Moon KA, Guallar E, Umans JG, Devereux RB, Best LG, Francesconi KA, et al. Association Between Exposure to Low to Moderate Arsenic Levels and Incident Cardiovascular Disease: A Prospective Cohort Study. Ann Intern Med. 2013 Sep 24.

16-Zhou Xh, Obuchowski NA, McClish DK. Statistical Methods in Diagnostic Medicine. New York: John Wiley and Sons, Inc, 2002.

17- Sigmon C, Patch S. A pilot survey of in-service home arsenic tracked in from chromated copper arsenate-treated decks. J Environ Health. 2010 JanFeb. 72(6): 18-22.

18-Rodrigues EG, Bellinger DC, Valeri L, Hasan MO, Quamruzzaman Q, Golam $M$, et al. Neurodevelopmental outcomes among 2- to 3-yearold children in Bangladesh with elevated blood lead and exposure to arsenic and manganese in drinking water. Environ Health. 2016 Mar 12. 15:44.

19-Hall M, Chen Y, Ahsan H, et al: Blood arsenic as a biomarker of arsenic exposure: results from a prospective study. Toxicology 2006;225:225-233. 